\title{
BIOMIMETIC SYNTHESIS AND ANTIBACTERIAL PROPERTIES OF STRONTIUM OXIDE NANOPARTICLES USING OCIMUM SANCTUM LEAF EXTRACT
}

\author{
APSANA $\mathrm{G}^{1,2}$, GEORGE PP ${ }^{1 *}$, DEVANNA $\mathrm{N}^{2}$, YUVASRAVANA $\mathbf{R}^{1,2}$ \\ ${ }^{1}$ Department of Chemistry, Madanapalle Institute of Technology and Science, Madanapalle - 517 325, Andhra Pradesh, \\ India. ${ }^{2}$ Department of Chemistry, Jawaharlal Nehru Technological University Anantapur - 515 002, Andhra Pradesh, India. \\ Email: georgepanikulangara@ yahoo.in
}

Received: 20 June 2017, Revised and Accepted: 14 December 2017

ABSTRACT

Objective: The investigation and synthesis of nanoparticles using green chemical methods is an emerging field due to ecologically derived materials. In the present study, the reaction under microwave irradiation technique is proposed for synthesizing the strontium oxide nanoparticles (SrO NPs) by reacting the strontium nitrate powder with Ocimum sanctum L. leaf extract followed by heat treatment at $500^{\circ} \mathrm{C}$ for $2 \mathrm{~h}$.

Methods: The crystalline nature, size, and morphological structure of the SrO powder sample were characterized by techniques such as powder X-ray diffraction (PXRD), scanning electron microscopy, ultraviolet (UV)-Vis spectroscopy, Fourier-transform infrared spectroscopy (FTIR) and photoluminescence (PL) spectral analysis. To investigate the antibacterial properties of SrO NPs, pathogens such as Escherichia coli, Staphylococcus aureus, Pseudomonas aeruginosa, Proteus vulgaris, Klebsiella pneumonia, and Morganella morganii was tested in Mueller-Hinton disc diffusion method.

Results: The particle size of the SrO NPs is calculated to be $42 \mathrm{~nm}$ using Debye-Scherrer equation. The SrO NPs exhibited absorption peak in the range of 250-350 nm centered at $274 \mathrm{~nm}$ in UV region. In addition, it is demonstrated that band gap energy was calculated to be 5.39 eV from Tauc's plot. The SrO NPs has shown the efficient antibacterial effect by inhibiting zone against Gram-negative bacteria.

Conclusion: The main aim of the study is to synthesize cost-effective and eco-friendly green synthesis of SrO NPs from the OS (O. sanctum) leaf extract and their characterization. The mechanism for the formation of SrO NPs in the presence of eugenol as reducing agent is also discussed. The present green chemical approach using plant-based materials for the synthesis of nanoparticles enhances the eco-friendliness, compatibility, effectiveness, and reduces the toxicity.

Keywords: Strontium oxide nanoparticles, Microwave irradiation, Antibacterial activity, Photoluminescence spectra, Reducing agent, Bandgap.

(c) 2018 The Authors. Published by Innovare Academic Sciences Pvt Ltd. This is an open access article under the CC BY license (http://creativecommons. org/licenses/by/4. 0/) DOI: http://dx.doi.org/10.22159/ajpcr.2018.v11i3.20858

\section{INTRODUCTION}

Green chemical reactions have been gained significant enthusiasm in the synthesis of a wide variety of transition metal oxide nanoparticles. The advances in synthesis approaches of nanomaterials have been essential in an enhancement of novel chemical and physical properties [1- 6]. Initially, the main attention was focused on the synthesis of transition metal oxide nanoparticles such as strontium oxide (SrO) due to their structural flexibility and potential applications. As far as, $\mathrm{SrO}$ is an important material and widely studied due to promising applications in gas sensors, electrodes for lithium-ion batteries, solar cells, doped dye- sensitized solar cells, transistors, catalyst supports, supercapacitors, and semiconductors [7-10]. Recently, Athar reported the sol-gel synthesis method of SrO NPs [11] using strontium chloride hexahydrate and potassium hydroxide pellets by dissolving in water and toluene followed by calcination at the temperature of $700^{\circ} \mathrm{C}$, and the nanoparticles were analyzed for their optical and thermal properties. Whereas, Nemade and Waghuley reported the one-pot chemical precipitation synthesis using hexamethylenetetramine [12].

There is a drawback that the majority of these synthetic methods requires high-temperature conditions, organic solvents, highly sensitive precursors, toxic reducing agents, special atmospheric conditions, and several steps to perform an experiment. Most of these chemical reducing agents and solvents possess a biological risk and hazardous to the environment. To overcome this drawback, nowadays many research communities have been paid considerable attention for the progress of new and simple approaches for the synthesis of the various nanoparticles using plant materials such as Punica granatum, Ocimum sanctum,
Carica papaya, and Brassica oleracea as a reducing agents [13-16] and is an important step on the way to the synthesis of new morphology and nanosize materials to enhance their properties [17-20]

However, the current work is to integrate the green chemical synthesis route for the preparation of SrO NPs in an efficient approach using the microwave oven at ambient temperature. There is very few less volume of literature is available for the synthesis of SrO NPs, and those methods have their own limitations.

Moreover, the present study elucidates the use of OS leaf extract as reducing and stabilizing agent due to the presence of important constituents such as eugenol, alkaloids, and terpenoids [21]. These phenolic compounds have pharm logical, medicinal, antibacterial, and an antioxidant effect [21]. Bindhani and Panigrahi suggested that the reducing property of the OS leaf extract was associated with their specific phenolic composition such as eugenol [22]. Recently, Apsana et al. also reported the reduction of $\mathrm{Ca}$ and Co metal ions using OS leaf extract and further it is confirmed that the possible reducing agent is eugenol by characterizing OS leaf extract using ultraviolet (UV) spectral analysis [23]. According to our previous report [23], the UV-Vis spectra of OS leaf extract show the two peaks at $282 \mathrm{~nm}$ and $325 \mathrm{~nm}$, respectively. The peaks exhibited due to the presence of phenolic compounds such as eugenol, triterpenes, and flavonoids which are responsible for the reduction of metal ions. Based on this explored concept, in the present study, we have synthesized SrO NPs using OS leaf extract by reducing strontium metal ions.

To the best of our knowledge, this is the first time we are reporting antibacterial property of SrO NPs synthesized OS-mediated microwave 
green chemical method. It is concluded that the current article exploits the advantages of low-cost precursors, rapid reaction, and simple preparation technique. Further, this research study explored the mechanism for the formation of SrO by OS leaf extract and also antibacterial activities performed against a set of six various microorganisms to evaluating zone of inhibition

\section{EXPERIMENTAL}

Chemicals and materials

Strontium nitrate $\left(\operatorname{Sr}\left(\mathrm{NO}_{3}\right)_{2}\right)$ is used as the starting material (Merck Chemicals, India) and was used as received without any further purification. OS leafs were collected from the garden of Madanapalle Institute of Technology and Sciences, Madanapalle, Andhra Pradesh.

\section{Preparation of $O$. sanctum leaf extract}

Leafs of $O$. sanctum plants were used to make the aqueous extract. Approximately $10 \mathrm{~g}$ of the leaves were thoroughly washed 2-3 times in ordinary water and 2-3 times using distilled water to get rid of the dust particles and cut into fine pieces. The finely cut pieces were boiled in an Erlenmeyer flask with $100 \mathrm{~mL}$ of distilled water for 7-10 min and cooled to room temperature. The OS leaf extract was collected by filtration and directly used for the experimentation to reduce metal nitrate solution.

\section{Biosynthesis of metal oxide nanoparticles}

In a typical experiment, $5 \mathrm{~g}$ of strontium nitrate is dissolved in $20 \mathrm{ml}$ distilled water in a $250 \mathrm{ml}$ beaker. Then, $10 \mathrm{ml}$ of OS leaf extract was added dropwise into strontium nitrate solution under continuous stirring for $10 \mathrm{~min}$ at the room temperature. The mixture of a solution was transferred into a household microwave, then irradiated for about 5-10 min until the solution undergoes dehydration and decomposition reactions. The resultant residue was collected by centrifugation at 4500 RPM, by washing with distilled water, followed by ethanol to remove impurities. The dried product was annealed at $500^{\circ} \mathrm{C}$ for $2 \mathrm{~h}$. The green synthesis approach for the preparation of $\mathrm{SrO}$ sample has been adopted from our previously reported work $[24,25]$. The experimental procedure for the synthesis of SrO NPs is shown in Scheme 1.

The Scheme 2 represents the reduction of strontium nitrate into strontium ions to produce SrO NPs using phenolic compound such as eugenol which is present in OS leaf extract.

\section{CHARACTERIZATION}

The crystalline structure of the annealed $\mathrm{SrO}$ product was characterized by Bruker D8 diffractometer with $\mathrm{CuK} \alpha$ radiation operated at $2 \theta$ range from $10^{\circ}$ to $80^{\circ}$ using Powder X-ray diffraction (PXRD). The morphology of the sample was analyzed with Ziess-SEM instrument. Jasco FT/ IR-4200 instrument used to analyze Fouriertransform infrared spectroscopy (FTIR) measurements in the range of $400-4000 \mathrm{~cm}^{-1}$. The UV-Vis absorbance, reflectance, and photocatalytic absorption studies of SrO sample were recorded by Jasco UV 670 in the range of 200-800 $\mathrm{nm}$ at room temperature. The photoluminescence (PL) data recorded in the range of $220 \mathrm{~nm}-600 \mathrm{~nm}$ using Jasco spectro fluorometer FP- 6300 with the scanning speed of $100 \mathrm{~nm} / \mathrm{min}$. The microbial strains used in assay method are Staphylococcus aureus, Escherichia coli, Pseudomonas aeruginosa, Proteus vulgaris, Klebsiella pneumonia, and Morganella morganii were obtained from Department of Microbiology, Sri Venkateswara Institute of Medical Sciences, Tirupathi, Andhra Pradesh, India.

\section{Antibacterial activity}

The phytosynthesized SrO NPs were tested for antibacterial activity by disc diffusion method. Mueller-Hinton agar medium was prepared by dissolving $28 \mathrm{~g}$ of Mueller-Hinton agar in $1 \mathrm{~L}$ of distilled water by sterilizing in an autoclave at the temperature of $121^{\circ} \mathrm{C}$ for $15 \mathrm{~min}$. The culture of Gram-positive such as $S$. aureus and Gram-negative such as E. coli, P. aeruginosa, P. vulgaris, K. pneumonia, and M. morganii were inoculated into broth medium (peptone water) from culture collection. Then, the broth is left for $1 \mathrm{~h}$ until the turbidity is equal to that

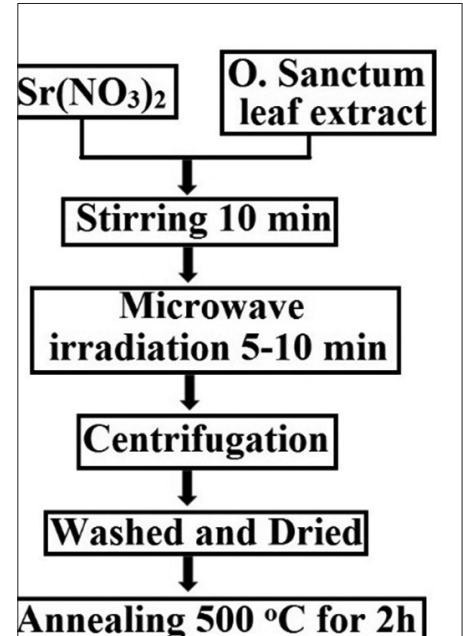

Scheme 1: Schematic representation of experiment procedure for strontium oxide nanoparticles

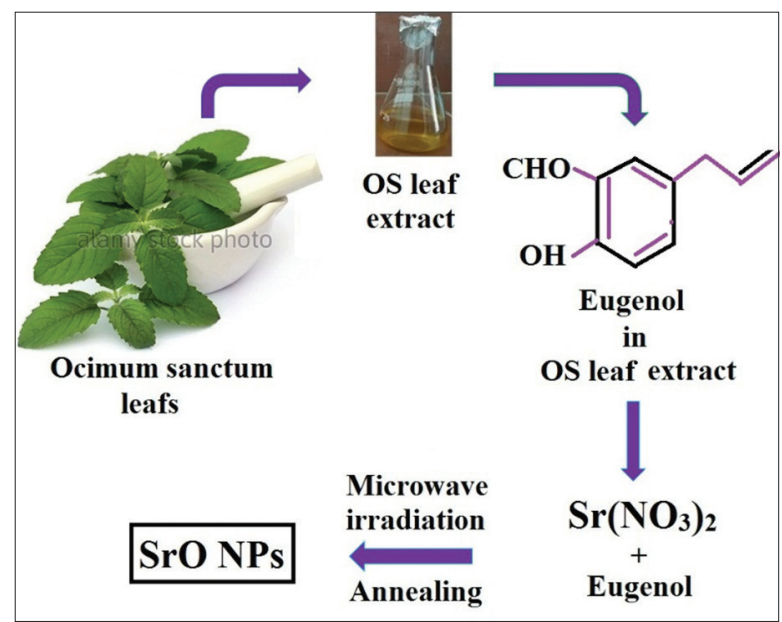

Scheme 2: Schematic representation of the synthesis procedure of strontium oxide nanoparticles using Ocimum sanctum leaf extract

0.5 McFarland standard. The MIC standards of OS leaf extract synthesized SrO NPs against the bacteria was determined to be $50 \mu \mathrm{g} / \mathrm{mL}$.

After solidification of broth medium, all the inoculated cultures were grown on Mueller-Hinton agar medium. Then, the disc diffusion was performed by placing discs of SrO NPs in six different types of microorganisms using a standard antibiotic on the surface of the agar plates and incubated for overnight at $37^{\circ} \mathrm{C}$ and the zones of inhibition were measured.

The antibiotic discs such as ampicillin, vancomycin, erythromycin, tetracycline, penicillin, cotrimoxazole, and linezolid were placed on the agar plates of $S$. aureus. The standard antibiotics such as cotrimoxazole, cefoperazone/sulbactam, amikacin, amoxicillin, nalidixic acid, cefotaxime, ciprofloxacin, and gentamicin were used in E. coli, P. vulgaris, K. pneumonia, and M. morganii culture agar plates. In addition, gentamicin, polymyxin, imipenem, ciprofloxacin, netilmicin, ceftazidime, and cotrimoxazole were used on the agar plates of P. aeruginosa culture

\section{RESULTS AND DISCUSSION}

\section{PXRD}

The crystalline nature of the PXRD pattern of the microwaveirradiated OS leaf extracted SrO NPs presented in Fig. 1. All the main 
peaks, cell parameters, and peak intensities are matched well with SrO [JCPDS no 00-006-0520]. The diffraction peaks at $2 \theta$ values $32.85^{\circ}$, $38.74^{\circ}, 46.95^{\circ}$, and $58.40^{\circ}$ are assigned to (011), (112), (202), and (113) planes of SrO, respectively. The PXRD of SrO NPs is similar to that of a previously reported XRD pattern of SrO synthesized in sol-gel method [11].

The average crystallite size of $\mathrm{SrO}$ NPs is calculated using Debye- Scherrer equation, as demonstrated follows,

$$
\mathrm{D}=\frac{0.94 \lambda}{\beta_{1 / 2} \operatorname{Cos} \theta}
$$

Where, $\mathrm{D}=$ average crystallite size, $\lambda=$ wavelength of the $\mathrm{X}$-ray diffraction, $\theta=$ diffraction angle, and $\beta=$ full-width at half maximum. The average crystallite size calculated to be $42 \pm 2 \mathrm{~nm}$ for SrO NPs.

\section{Scanning electron microscopy (SEM)}

Fig. 2 depicts the SEM image of the SrO NPs. The shape of the SrO NPs is a nearly spherical arrangement on the smooth surface which bound parallel together as small layer formation with the diameter in the range of $25-50 \pm 2.5 \mathrm{~nm}$ and having an average diameter of $75 \pm 2.5 \mathrm{~nm}$. The SrO NPs prepared by Granados-Correa and Bonifacio-Martinez. in combustion method has 1-30 $\mu \mathrm{m}$ in size particles with smooth surface square alumina-like aggregates [26]. Granados-Correa's synthetic strategy involves the combustion reaction of strontium nitrate and urea at $800^{\circ} \mathrm{C}, 900^{\circ} \mathrm{C}$, and $1000^{\circ} \mathrm{C}$ for $5 \mathrm{~min}$ and the product formed at $800^{\circ} \mathrm{C}$ and $900^{\circ} \mathrm{C}$ have mixture of three different phases are existing such as $\mathrm{SrO}, \mathrm{SrCO}_{3}$, and $\mathrm{Sr}(\mathrm{OH})_{2}$ ) and at $1000^{\circ} \mathrm{C}$ only $\mathrm{SrO}$ phase is exist. The present microwave green synthetic approach afford use of simpler reducing agent which is non-hazardous, low-cost, and also require only $500^{\circ} \mathrm{C}$ of temperature for the formation of single phase SrO NPs.

\section{Energy dispersive X-ray (EDX) spectroscopy}

The elemental compostion of SrO NPs are determined by using energy dispersive X-ray spectroscopy as shown in Fig. 3. The EDX analysis indicates the presence of $\mathrm{Sr}$ and $\mathrm{O}$ elements, respectively and no other

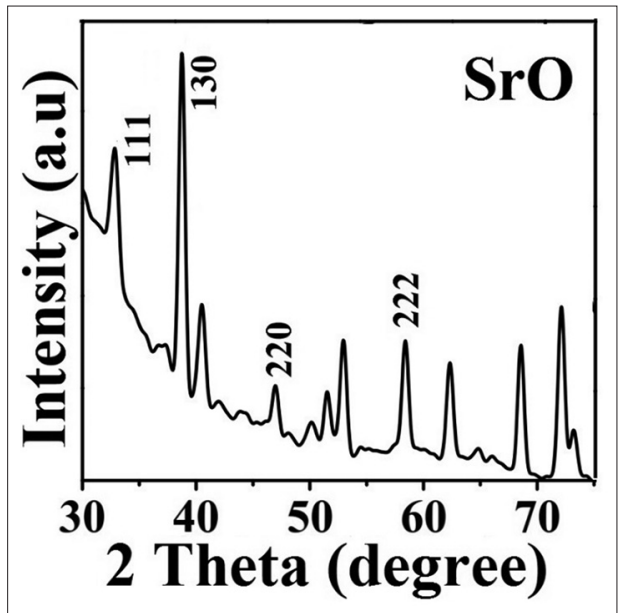

Fig. 1: X-ray diffraction pattern of strontium oxide nanoparticles
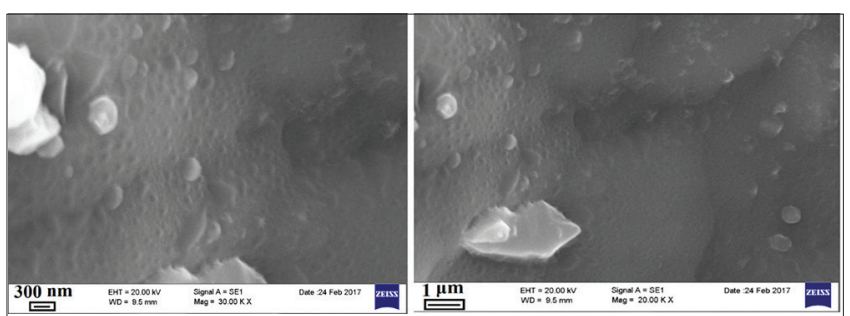

Fig. 2: Scanning electron microscopy image of strontium oxide nanoparticles impurities are detected. The $\mathrm{Sr} / 0$ atomic ratio in the $\mathrm{SrO}$ NPs obtained from EDX analysis was 1:1 in agreement with the metal oxide formula. The EDX analysis confirms that the SrO particles consist only of metal and oxygen components which indicates the purity of the synthesized sample.

\section{FTIR}

The FTIR spectra of SrO NPs were shown in Fig. 4. SrO NPs has peaks between 500 and $1000 \mathrm{~cm}^{-1}$ at $428.20 \mathrm{~cm}^{-1}, 732.95 \mathrm{~cm}^{-1}, 810.10 \mathrm{~cm}^{-1}$, and $856.39 \mathrm{~cm}^{-1}$ are attributed to bending vibrations of Sr-O [22]. The sharp absorption bands at $1330.88 \mathrm{~cm}^{-1}, 1433.11 \mathrm{~cm}^{-1}, 1737.86 \mathrm{~cm}^{-1}$, and $3383.14 \mathrm{~cm}^{-1}$ can be assigned to $\mathrm{O}-\mathrm{H}$ bending and $\mathrm{C}-\mathrm{O}$ is stretching vibrations [27]. The $\mathrm{O}-\mathrm{H}$ and $\mathrm{C}-\mathrm{O}$ stretching bonds of the FTIR spectrum is very similar to our previously reported FTIR spectrum of OS leaf extract [23]. The presence of $\mathrm{C}-\mathrm{O}, \mathrm{O}-\mathrm{H}, \mathrm{C}-\mathrm{C}$, and $\mathrm{C}-\mathrm{N}$ peaks indicates that all SrO NPs are prepared using the OS leaf extract as reducing agent and also acting as capping agent on the surface of metal oxide nanoparticles.

\section{Optical properties}

The UV-Visible absorbance and reflectance spectra of the SrO NPs synthesized in the present study using OS leaf extract was shown in Fig. $5 \mathrm{a}$ and b, respectively. The UV-Vis absorption peak was observed at $274 \mathrm{~nm}$ and the transmittance at $296 \mathrm{~nm}$ for the synthesized SrO NPs. The peak at $274 \mathrm{~nm}$ occurs due to the quantum size effect of monodispersed colloidal particles and the transmittance peak indicates the controlled size of particles and purity of the sample [28]. Athar

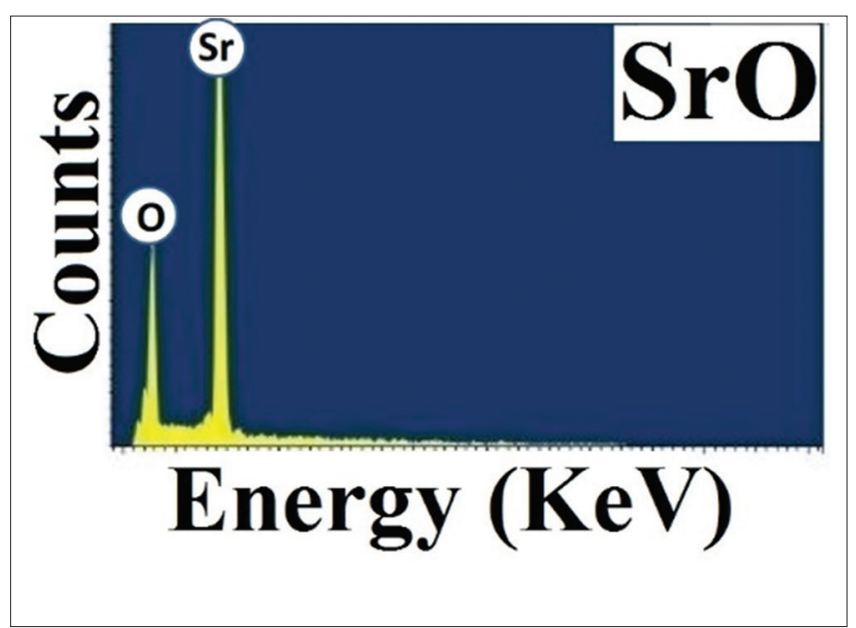

Fig. 3: Energy dispersive X-ray spectrum of strontium oxide nanoparticles

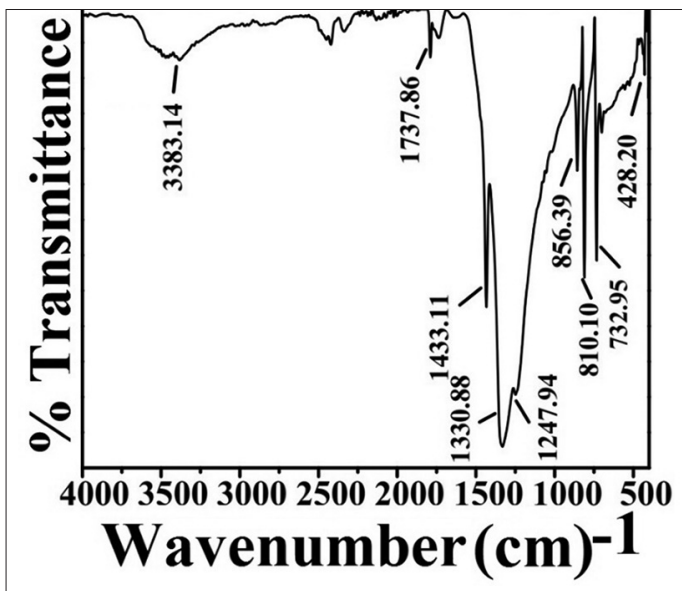

Fig. 4: Fourier-transform infrared spectrum of strontium oxide nanoparticles 


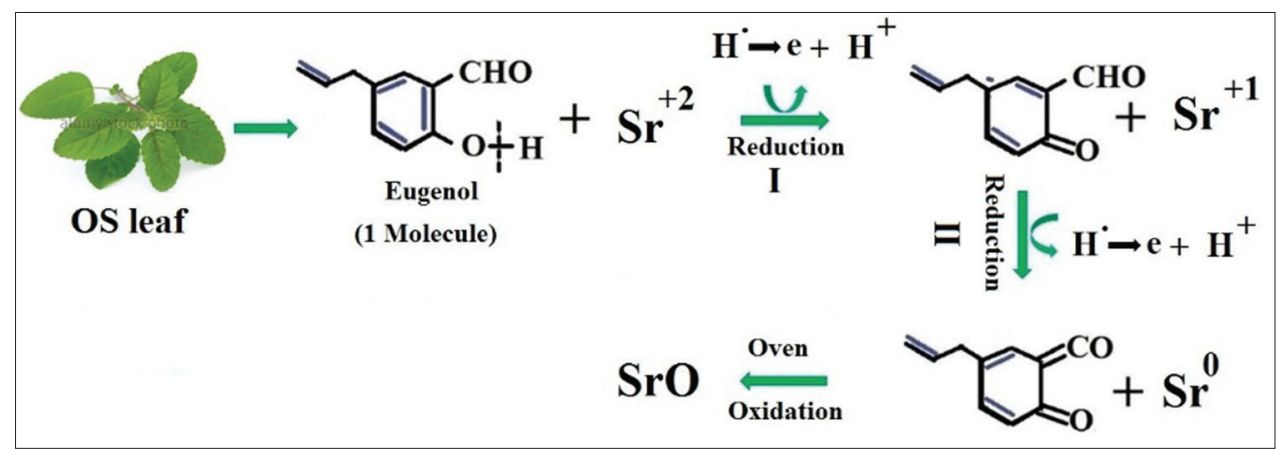

Scheme 3: Reduction of strontium ions using Ocimum sanctum leaf extract

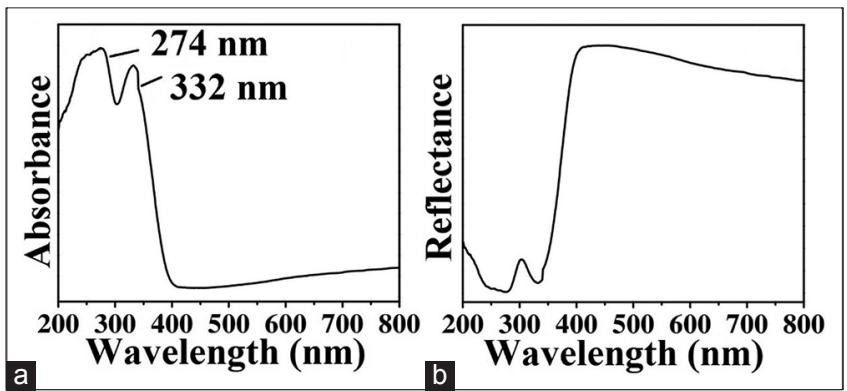

Fig. 5: UV-visible spectrum of strontium oxide nanoparticles. (a) Absorbance (b) reflectance spectrum

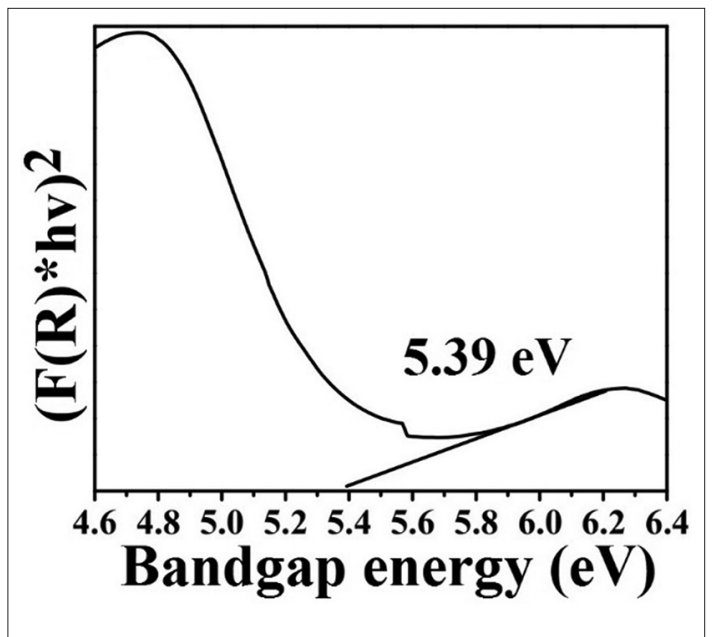

Fig. 6: $(\alpha h v)^{2}$ versus (hv) spectra of strontium oxide nanoparticles

reported the UV-Vis spectrum with broad spectrum at $265 \mathrm{~nm}$ and $290 \mathrm{~nm}$ which is due to the quantum size effect and surface morphology of the particles, respectively [11]. It is also explained that the peak at $290 \mathrm{~nm}$ is an indication of the purity and controlled size of the particles. The SrO NPs synthesized in the present study also exhibited two transmittance peaks around $270 \mathrm{~nm}$ and $330 \mathrm{~nm}$ which indicates the synthesized SrO NPs are pure and nano in their size.

From the diffuse reflectance (R) of the respective metal oxide nanoparticles, the band gap energy is calculated with the Kubelka- Munk function $F(R)$ in the equation $F(R)=(1-R)^{2} / 2 R$. The plot of $\left(F(\mathrm{R})^{*} h v\right)^{2}$ versus $h v$ is drawn and the linear regions are extrapolated to the zero ordinate to obtain $\mathrm{E}_{\text {g.dir }}$ for a direct allowed transitions. Fig. 6 shows the Tauc's plot of SrO NPs. From the Fig. 6, the band gap energy of SrO NPs is found to be $5.39 \mathrm{eV}$ which is higher than the bulk SrO $(1.8 \mathrm{eV})$ material. Due to the quantum confinement effect, the trend of decreasing particle size influences the increase in the band gap energy of the sample. The higher value of band gap energy indicates that the SrO NPs synthesized in the present work are in nanophase.

The synthesized SrO NPs are examined by PL spectra at room temperature to study their nature of emission and is presented in Fig. 7. The PL spectrum indicates the excitation of SrO NPs occurs at $350 \mathrm{~nm}$ with broad emission band in the range of $455-480 \mathrm{~nm}$ which is due to exciton recombination, and the luminescence is also similar as predicted by the Nemade and Waghuley [12]. According to the Nemade and Waghuley of $\mathrm{SrO}$ quantum dots synthesized in one-pot chemical precipitation method were shown emission from $320 \mathrm{~nm}$ to $500 \mathrm{~nm}$. In addition, it is also explained that the range of this emission frequency is influenced by the band gap energy, and this can be altered by changing the surface chemistry and size of the quantum dots. The small difference appeared in the emission spectrum of the current approach compared to that of Nemade and Waghuley approach due to the variation obtained in band gap energy, surface morphology, and the particle size of the SrO NPs.

Evaluation of antibacterial activity of phytosynthesized SrO nanoparticles

Strontium compounds demonstrate the antibacterial activity against various pathogens $[29,30]$. The present work explored the antibacterial activity of SrO NPs annealed at $500^{\circ} \mathrm{C}$ for $2 \mathrm{~h}$ and were tested against Gram-positive bacteria (S. aureus) and Gram-negative bacteria (E. coli, P. aeruginosa, P. vulgaris, K. pneumonia, and M. morganii).

The antibacterial results revealed that Gram-negative bacteria are more susceptible to SrO NPs. It is also found that the antibacterial activity of SrO NPs shows much higher activity against Gram-negative pathogens than the Gram-positive pathogen. The differences in deactivation efficiency of bacteria are attributed due to their cell wall structure. The Gram-positive and Gram-negative bacteria contain similar internal structure, while the outer cell wall membrane is constructed with various layers. The Gram-positive bacterial cell wall is constructed with a thick peptidoglycan layer containing teichoic and lipoteichoic acids, and the transport system is highly restricted by this membrane. However, the cell wall of Gram-negative bacteria is made of a thin layer of peptidoglycan, which is attached to the outer membrane with the composition of lipopolysaccharide, phospholipids, and proteins that are a distinctive property of Gram-negative bacteria and can be damaged more easily.

The antibacterial effect of the SrO sample was examined using Gram- positive and Gram-negative bacteria as shown in Fig. 8 . Among the different bacterial strains, the Gram-positive pathogens $P$. aeruginosa (10 $\mathrm{mm} \pm 0.25), K$. pneumonia (10 $\mathrm{mm} \pm 0.25)$, and M. morganii ( $9 \mathrm{~mm} \pm 0.25$ ) were inhibited highest zone of inhibition. The minimum zone of inhibition was shown by Gram-positive $P$. vulgaris pathogen ( $5 \mathrm{~mm} \pm 0.25)$, whereas SrO NPs are not shown a zone of inhibition against $S$. aureus and E. coli pathogens. The SrO NPs comparatively exhibit good antibacterial property like other standard antibiotics. 
The differences in the thickness, morphology, and resistance of bacterial cell wall lead to the inactivation of the bacterial growth. The number of potential reactive oxygen species is produced on the $\mathrm{SrO}$ particle surface results in the higher antibacterial activities of Gram-negative bacteria due to the thin peptidoglycan layer than the Gram-positive. Pal et al. reported the same type of response against Gram-negative and Gram-positive bacteria [31]. This resulted in the absence of the zone of inhibition against $S$. aureus and E. coli, whereas less zone of inhibition against $P$. aeruginosa, K. pneumonia, M. morganii, and P. vulgaris compared to that of SrO NPs.

\section{Mechanism}

The formation of SrO NPs by the reduction of strontium ions using OS extract is shown in Scheme 3. Primarily the reduction process has been initiated while the strontium nitrate solution along with the extract. In the first step, one molecule of eugenol (extract) undergoes fission reaction of $\mathrm{O}-\mathrm{H}$ bond to release hydrogen radical which further converted into one proton and electron. The first electron reduces the $\mathrm{Sr}^{+2}$ into $\mathrm{Sr}^{+1}$ ions. In the second step, fission reaction of the aldehydic

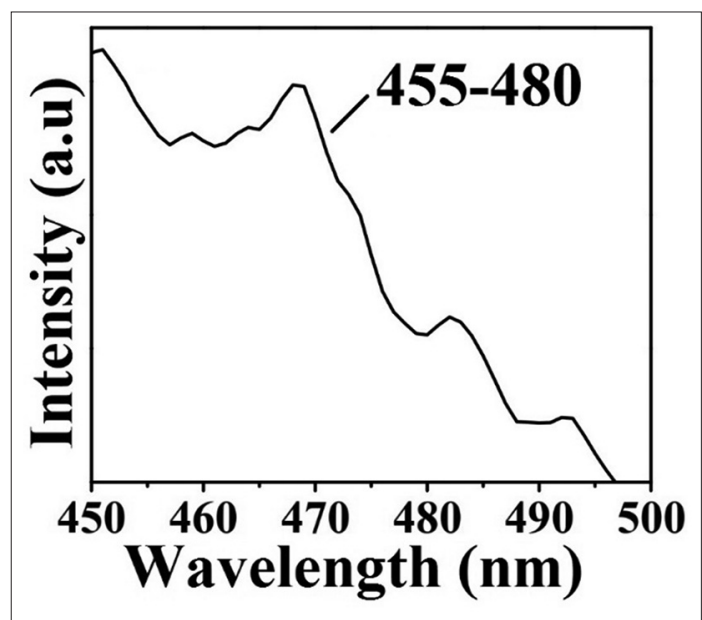

Fig. 7: Photoluminescence spectrum of strontium oxide nanoparticles functional group leads to the formation of the second electron, which reduces the $\mathrm{Sr}^{+1}$ ions into $\mathrm{Sr}^{0}$. For the reduction of $\mathrm{Sr}$ metal ions, only one molecule of eugenol is required. After the complete reduction process, in microwave oven heating, immediately metal ions get oxidized by atmospheric oxygen to form SrO NPs due to surface plasmon resonance phenomena and stabilizes metal ions against Van der Waals force [32].

- $\quad \mathrm{I} \mathrm{Sr}^{+2} \rightarrow \mathrm{Sr}^{0}$ (reduction)

- $\quad$ II $\mathrm{HNO}_{3} \rightarrow \mathrm{H}^{+}+\mathrm{NO}_{3}{ }^{-}$

- $\quad$ III $\mathrm{NO}_{3}{ }^{-} \rightarrow \mathrm{NO}_{2} \uparrow+\mathrm{O}_{2} \uparrow$

- $\quad \mathrm{IV} \mathrm{nSr}{ }^{0}+\mathrm{nO}_{2} \rightarrow \mathrm{n} \mathrm{SrO}(\mathrm{n}=1,2,3 \ldots)$

\section{CONCLUSION}

In summary, the SrO NPs synthesized through a microwave technique based on a reaction between strontium nitrate and OS leaf extract. The mechanism for the formation of SrO NPs also has been discussed. The biosynthesis of SrO NPs has provided a low-cost, convenient, eco- friendly, and effective technique than the other chemical methods. The band gap energy concludes that biosynthesized SrO NPs in the present study have a higher band gap than the bulk material which confirms the formation of nano-size particles. The PXRD and EDX results indicate the purity of the SrO NPs synthesized in the current approach. The PL of SrO indicates that the emission bands occur in the visible region at 455-480 $\mathrm{nm}$. Moreover, the biosynthesized SrO NPs showed significant antibacterial activity against Gram-negative bacteria such as P. aeruginosa, K. pneumonia, M. morganii, and P. vulgaris than that of the Gram-positive bacteria.

\section{ACKNOWLEDGMENT}

The authors extend their sincere thanks for the financial support of this work under UGC major research project (MRP-MAJOR CHEM- 2013- 25694) and MANF fellowship (MANF- 2015- 17- AND- 58287). The authors also gratefully acknowledge their thanks to the management, Madanapalle Institute of Technology and Sciences, Madanapalle, Chittoor, Andhra Pradesh, India, for supporting to complete this research work. G. Apsana is also thankful to VIT, Vellore, for PXRD, FTIR, and UV-Vis measurements, SV University,
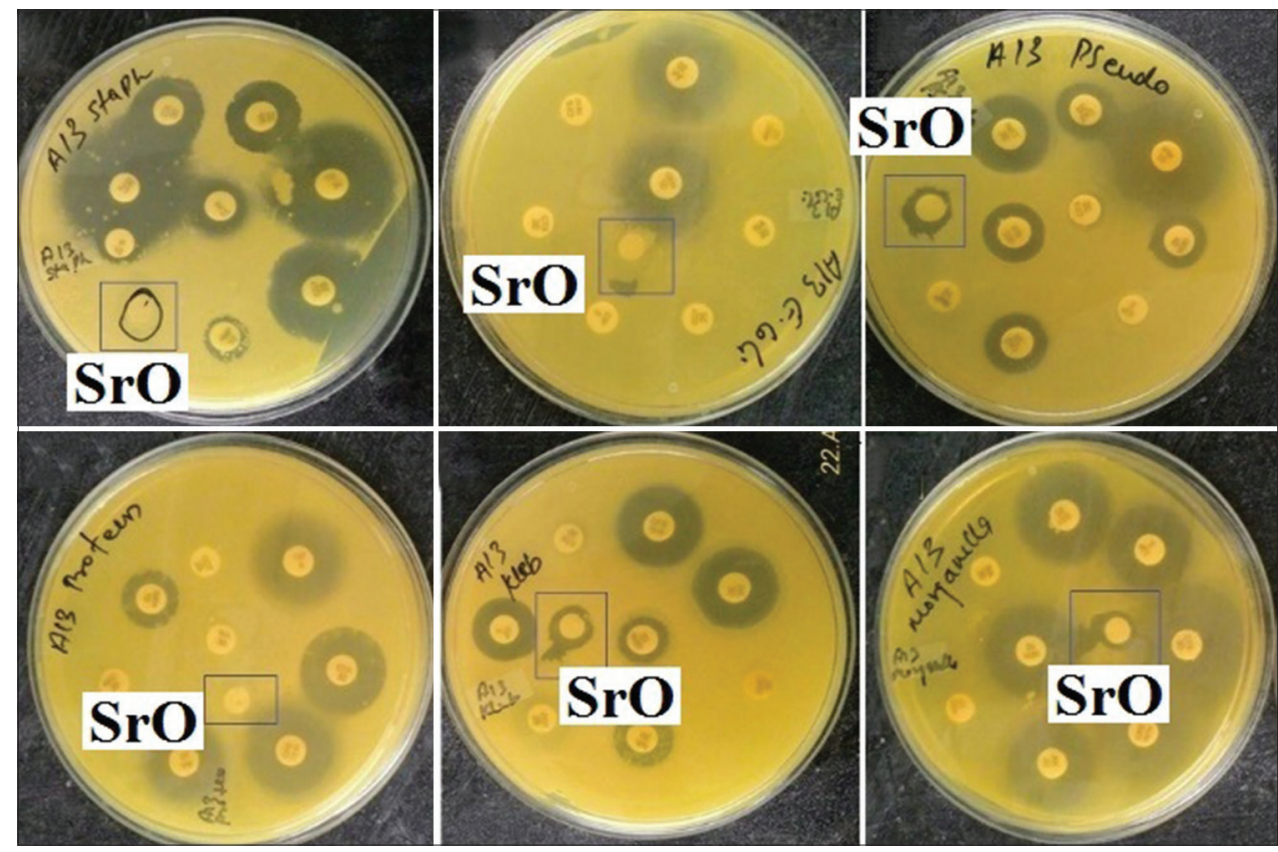

Fig. 8: Antibacterial activity (zone of inhibition) of strontium oxide nanoparticles (a) Staphylococcus aureus, (b) Escherichia coli, (c) Pseudomonas aeruginosa, (d) Proteus Vulgaris, (e) Klebsiella pneumonia, (f) Morganella morganii 
Tirupathi, for SEM measurements and PL spectroscopy. The authors are also thanking Department of Microbiology, Sri Venkateswara Institute of Medical Sciences, Tirupathi, and Andhra Pradesh, India, for providing antibacterial studies.

\section{AUTHOR CONTRIBUTIONS}

P.P. George has been designed the concept of the work and also has made a revision of the manuscript. G. Apsana has performed experimental work, analysis of data including writing manuscript. N. Devanna has been supported for the completion of this work and helped in revision of the manuscript. R. Yuvasravana also did technical help, writing and editing assistance, general support for the completion of the manuscript.

\section{CONFLICTS OF INTERESTS}

Authors declared that there are no potential conflicts of interest.

\section{REFERENCES}

1. George PP, Pol VG, Gedanken A. Synthesis and characterization of $\mathrm{Nb}_{2} \mathrm{O}_{5} @ \mathrm{C}$ core-shell nanorods and $\mathrm{Nb}_{2} \mathrm{O}_{5}$ nanorods by reacting $\mathrm{Nb}(\mathrm{OEt})_{5}$ via RAPET (reaction under autogenic pressure at elevated temperatures) technique. Nanoscale Res Lett 2007;2:17-23.

2. George PP, Pol VG, Gedanken A, Gabashivili A, Cai M, Mance AM, et al. Selective coating of anatase and rutile $\mathrm{TiO}_{2}$ on carbon via ultrasound irradiation: Mitigating fuel cell catalyst degradation. J Fuel Cell Sci Tech 2008;5:41012-20.

3. George PP, Pol VG, Koltypin Y, Shirly Ben-David MS, Genish I, Gedanken A. Chemical reactions under autogenic pressure at elevated temperature to fabricate photo-luminescent $\mathrm{Ga}_{2} \mathrm{O}_{3}$ nanocrystals and their coatings. RSC Adv 2011;1:619-24.

4. George PP, Gedanken $\mathrm{A}$. $\mathrm{Ta}_{2} \mathrm{O}_{5}$ nanobars and their composites: Synthesis and characterization. J Nanosci Tech 2008;8:5801-6.

5. George PP, Gedanken A. Synthesis, characterization, and photoluminescence properties of $\operatorname{In}_{2} \mathrm{O}_{3}$ nanocrystals encapsulated by carbon vesicles and neat $\operatorname{In}_{2} \mathrm{O}_{3}$ nanocrystals generated by the RAPET technique. Eur J Inorg Chem 2008;6:919-24.

6. George PP, Gedanken A, Perkas N, Zhong Z. Selective oxidation of $\mathrm{CO}$ in the presence of air over gold-based catalysts $\mathrm{Au} / \mathrm{TiO}_{2} / \mathrm{C}$ (sonochemistry) and $\mathrm{Au} / \mathrm{TiO}_{2} / \mathrm{C}$ (microwave). Ultrason Sonochem 2008;15:539-47.

7. Laurent C, Peigney A, Quenard O, Rousset A. Synthesis and characterization of alumina matrix nanocomposites containing carbon nanotubes. Key Eng Mater 1997;132:157-60.

8. Schmid HK, Aslan M, Assmann S, Nab R, Schmidt H. Microstructural characterization of $\mathrm{Al}_{2} \mathrm{O}_{3}-\mathrm{SiC}$ nan composites. Eur Ceram Soc1988; 18:39-49.

9. Yang Y, Chen $\mathrm{H}$, Zhao B, BaO X. Size control of $\mathrm{ZnO}$ nanoparticles via thermal decomposition of zinc acetate coated on organic additives. J Crystal Growth 2004;263:447-53

10. Prasad KR, Miura N. Electrochemical synthesis and characterization of nanostructured tin oxide for electrochemical redox supercapacitors. Electrochem Commun 2004;6:849-52.

11. Athar T. Synthesis and characterization of strontium oxide nanoparticles via wet process. Mater Focus 2013;2:450-3.

12. Nemade KR, Waghuley SA. UV-VIS spectroscopic study of one-pot synthesized strontium oxide quantum dots. Results in Phy 2013;3:52-4.

13. Yuvasravana R, George PP, Devanna N. Synthesis and characterization of spinel metal aluminate by a simple microwave assisted green synthesis. Mater Today Proc 2017:4:10664-71.
14. Apsana G, George PP, Devanna N, Yuvasravana R. Enhanced morphology and efficient one-pot microwave Green synthesis of $\mathrm{Ag}_{3} \mathrm{PO}_{4}$ nanocubes and their optical and photocatalytic properties. J Bionanosci 2017;11:1-7.

15. Sridevi A, Sandhya A, Devi PS. Characterization and antibacterial studies of leaf assisted silver nanoparticles from Carica papaya: A green synthetic approach. Int J Pharm Pharm Sci 2015;7:143-6.

16. Bavani L, Inbakandan D, Renuka Devi J. In vivo toxicity studies of biosynthesized silver nanoparticles using Brassica oleraceae in zebra fish model. Int J Pharm Pharm Sci 2015;7:425-30.

17. Mayuri M, Rahul RD, Vishwas P, Snehal S, Nirmala RD, Rasika T. Comparative evaluation of antibacterial properties of different extracts of Mimusops elengi (bakul) and Ehretia laevis (ajaan) against salivary microflora. Asian J Pharm Clin Res 2015;8:217-9.

18. Elizabath A, Mythili S, Sathiavelu A. Synthesis of silver nanoparticles from the medicinal plant Bauhinia acuminata and Biophytum sensitivum-a comparative study of its biological activities with plant extract. Int J Appl Pharm 2017;9:22-9.

19. Kamath KK, Shabaraya AR. Comparison of antibacterial activity of leaves extracts of Tectona grandis, Mangifera indica, and Anacardium occidentale. Int J Curr Pharm Res 2017;9:36-9.

20. Kathirvel P. Chemical composition of essential oil of Ocimum basilicum L. (Basil) and its biological activities-an overview. J Crit Rev 2016;3:56-62.

21. Das SK, Vasudevan DM. Tulsi: The Indian holy plant. Nat Prod Radiance 2006;5:279-83.

22. Bindhani BK, Panigrahi AK. Biosynthesis and characterization of silver nanoparticles (SNPs) by using Leaf extracts of Ocimum sanctum L (Tulsi) and study of its antibacterial activities. Nanomed Nanotechnol 2015;S6:008.

23. Apsana G, George PP, Devanna N. Green synthesis and thermo, optical properties of $\mathrm{M}_{2} \mathrm{P}_{2} \mathrm{O}_{7}[\mathrm{M}=\mathrm{Ca}$ and $\mathrm{Co}]$ nanoparticles. Int J Pharm Bio Sci 2017;8:148-59

24. Yuvasravana R, George PP. A green protocol for synthesis of $\mathrm{MAl}_{2} \mathrm{O},[\mathrm{M}=\mathrm{Cu}$ and $\mathrm{Co}]$ spinels under microwave irradiation method. Int J Nanosci 2016;15:1650033.

25. Yuvasravana R, George PP, Devanna N. Biosynthesis of MO- $\mathrm{MCo}_{2} \mathrm{O}_{4}[\mathrm{M}=\mathrm{Zn}$ and $\mathrm{Cu}]$ Composites from peel extract of pomegranate fruits -"Punica granatum". Int J Innov Res Sci Eng Tech 2017;6:5516-24

26. Granados-Correa F, Bonifacio-Martinez J. Combustion synthesis process for the rapid preparation of high-purity $\mathrm{SrO}$ powders. Mater Sci Poland 2014;32:682-7.

27. Alavi MA, Morsali A. Syntheses and characterization of $\mathrm{Sr}(\mathrm{OH})_{2}$ and $\mathrm{SrCO}_{3}$ nanostructures by ultrasonic method. Ultrasonics Sonochem 2010;17:132-8.

28. Wang X, Song J, Gao L, Jin J, Zheng H, Zhang Z. Optical and electrochemical properties of nanosized $\mathrm{NiO}$ via thermal decomposition of nickel oxalate nanofibres. Nanotechnology 2005;16:37-9.

29. Lin Y, Yang Z, Cheng J, Wang L. Synthesis, characterization and antibacterial property of strontium half and totally substituted hydroxyapatite nanoparticles. J Wuhan Univ Tech Mater Sci Edu 2008;23:475-9.

30. Ravi ND, Balu R, Kumar TS. Strontium substituted calcium deficient hydroxyapatite nanoparticles: Synthesis, characterization and antibacterial properties. J Am Ceram Soc 2012;95:2700-8

31. Pal A, Pehkonen SO, Yu LE, Ray MB. Photocatalytic inactivation of gram positive and gram negative bacteria using fluorescent light. J Photochem Photobiol Chem 2007;186:335-41.

32. Mulvaney P. Surface plasmon spectroscopy of nanosized metal particles. Langmuir 1996;12:788-800. 